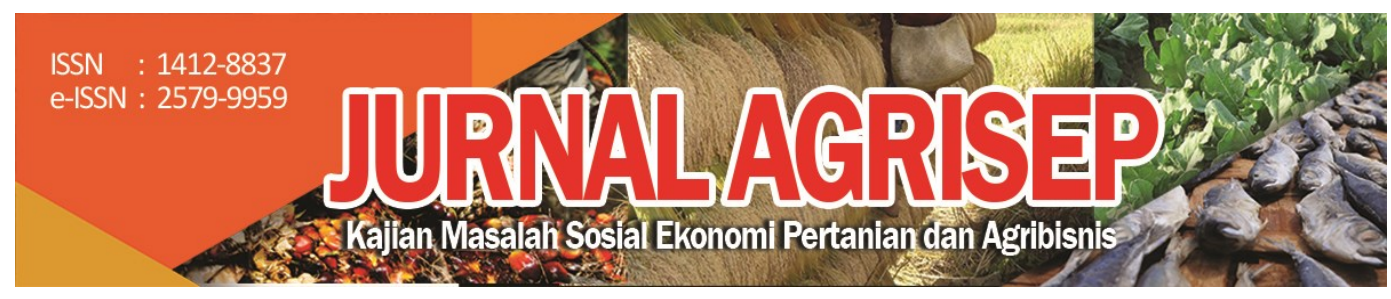

DOI: $10.31186 /$ jagrisep.20.2.411-420

\title{
PENGARUH PROGRAM KARTU TANI TERHADAP PENURUNAN BIAYA PUPUK PADA PETANI PADI
}

\section{Effect Of The Farmer's Card Program On Reducingfertilizer Costs On Rice Farmers}

\author{
Bayu Mahendra1) $\square$; Suprapto $^{2)}$; Hima Barima ${ }^{3)}$ \\ 1,2)Program Studi Agribisnis, Fakultas Sains dan Teknik, Universitas Perwira \\ Purbalingga, Jawa Tengah, Indonesia \\ 3) Program Studi Manajemen, Fakultas Ekonomi dan Bisnis, Universitas \\ Perwira Purbalingga, Jawa Tengah, Indonesia \\ Email: 31bayumahendra@gmail.com
}

\begin{abstract}
Fertilizer costs that must be borne by farmers are getting higher and higher and burdensome to farmers. Kartu Tani (Farm Card) is a government program as a form of protection for farmers.Based On 17 paragraph 2 of the Regulation of the Minister of Agriculture (Permentan) No. 10 of 2020. The purpose of this research is to find out how much influence the use of Kartu Tani has on reducing fertilizer costs for farmers. This research uses farmer respondents, with a total of 27 farmers based on consideration of the area of land cultivated and the similarity of commodities. Quantitative descriptive method was used by researchers in this study, so that it can describe the farming business carried out by farmers and the total costs incurred by farmers for the purchase of chemical fertilizers. The results of the descriptive analysis show a decrease in the average cost of fertilizer by IDR 1,316,296 from the cost of IDR 2,032,592 to IDR 716,296. The results of the t-test show the comparison that the costs incurred by farmers before the Kartu Tani program and after the Kartu Tani program are significant, this can be seen from the value of Sig. 0.045 or $<0.05$, then from the $T$ test results it can be said that the decrease in fertilizer costs is significant. The results of Wilcoxon's analysis showed that all respondents experienced a decrease in fertilizer costs, this was seen from the results of Negative Ranks, which were 27 of a total of 27 respondents.
\end{abstract}

Keywords: Farmer's Card, Cost Decrease, Wilcoxon, Fertilizer 


\begin{abstract}
ABSTRAK
Biaya pupuk yang harus ditanggung petani semakin lama semakin tinggi dan memberatkan petani. Kartu Tani merupakan program pemerintah sebagai bentuk perlindungan terhadap petani. Berdasarkan 17 ayat 2 Peraturan Menteri Pertanian (Permentan) Nomor 10 Tahun 2020. Tujuan dari penelitian ini adalah untuk mengetahui bagaimana banyak pengaruh penggunaan Kartu Tani dalam mengurangi biaya pupuk bagi petani. Penelitian ini menggunakan responden petani, dengan jumlah 27 petani berdasarkan pertimbangan luas lahan yang diusahakan dan kesamaan komoditas. Metode deskriptif kuantitatif digunakan peneliti dalam penelitian ini, sehingga dapat menggambarkan usaha tani yang dilakukan petani dan total biaya yang dikeluarkan petani untuk pembelian pupuk kimia. Hasil analisis deskriptif menunjukkan penurunan rata-rata biaya pupuk sebesar Rp 1.316.296 dari biaya $R p$ 2.032.592 menjadi $R p$ 716.296. Hasil uji t menunjukkan perbandingan biaya yang dikeluarkan petani sebelum program Kartu Tani dan setelah program Kartu Tani signifikan, hal ini terlihat dari nilai Sig. 0,045 atau <0,05, maka dari hasil uji T dapat dikatakan penurunan biaya pemupukan signifikan. Hasil analisis Wilcoxon menunjukkan bahwa seluruh responden mengalami penurunan biaya pemupukan, hal ini terlihat dari hasil Peringkat Negatif yaitu sebanyak 27 dari total 27 responden.
\end{abstract}

Kata Kunci :Kartu Tani, Penurunan Biaya, Wilcoxon, Pupuk

\title{
PENDAHULUAN
}

Pembangunan dan pemberdayaan pertanian di Indonesia memiliki tujuan untuk mewujudkan ketahanan pangan dan meningkatkan kesejahteraan petani serta seluruh lapisan yang mendukung kegiatan tersebut. (Ustriyana 2015), menyatakan bahwa komoditas yang seharusnya dikembangkan dalam rangka ketahanan pangan nasional adalah komoditas yang mempunyai potensi riil yang besar dan diusahakan secara masal oleh masyarakat. Padi merupakan komoditas penting yang menjadi makanan pokok hampir seluruh penduduk Indonesia (Purnamaningsih, 2016). Padi yang diolah menjadi beras sebagai sumber penyedia energi tertinggi dengan rata-rata konsumsi langsung rumah tangga pada tahun 2020 sebesar $94,9 \mathrm{~kg} / \mathrm{kapita} /$ tahun. Peningkatan produksi padi menjadi peluang yang besar untuk pengembangan ekonomi masyarakat petani tentunya. Melalui produk pertanian bernilai ekonomi tinggi ini diharapkan dapat memperbaiki pendapatan dan kesejahteraan masyarakat (Subowo, 2009).

Daerah istimewa Yogyakarta merupakan provinsi yang memiliki produktivitas padi paling rendah di pulau Jawa. Salah satu penyumbang penurunan produktivitas padi di Yogyakarta ialah Kulon progo yang megalami penurunan laju produksi sejak tahun 2020. Pada tahun 2018, produksi padi di Kabupaten kulon Progo tercatat 115.067 ton atau terdapat peningkatan produksi sebesar 1,51\% dibandingkan tahun 2017 yang mencapai 113.359 ton. Dari total 
produksi padi tersebut, sebanyak 114.806 ton merupakan padi sawah dan 261 ton padi ladang (BPS 2019). Pada tahun 2019 Pemerintah Kabupaten Kulon Progo melalui Badan Pusat Statistik (BPS) mencatat luas areal persawahan Kabupaten Kulon Progo tahun 2019 sebesar 11.047 Ha, jumlah tersebut sama dengan luas lahan persawahan pada tahun 2018 yaitu 11.047 Ha. Jumlah luas lahan persawahan yang tidak meningkat tentunya harus diimbangi dengan peningkatan produktivitas, agar kebutuhan pangan tetap dapat terpenuhi dari hasil petani lokal.

Pelaksanaan usahatani padi skala kecil dan menengah seringkali terkendala oleh faktor penghambat, seperti pupuk. Program kartu tani diluncurkan oleh pemerintah dengan tujuan pengalokasian pupuk bersubsidi dapat tepat sasaran dan tidak disalahgunakan. Penyalahgunaan pupuk bersubsidi sering terjadi, sehingga pengalokasian pupuk bersubsidi menjadi tidak tepat sasaran. Pupuk bersubsidi adalah pupuk yang dalam pendistribusian dan pengadaannya mendapat bantuan subsidi dari pemerintah(Agus, et al., 2018). Program ini dilakukan untuk memudahkan petani mendapatkan pupuk dengan harga yang terjangkau.

Penyaluran pupuk bersubsidi memiliki permasalahan klasik yaitu perencanaan, penyaluran, dan pengawasan(Darwis dan Saptana 2010). Permasalahan yang terjadi di Kabupaten Kulon Progo adalah kelangkaan pupuk bersubsidi dan harga pupuk non subsidi yang mahal. Program Kartu Tani yang dibuat oleh pemerintah bertujuan untuk memastikan petani mendapatkan kuota kebutuhan pupuk dan memastikan petani mendapatkan akses pembelian pupuk bersubsidi. Kartu Tani memiliki dasar dari beberapa kebijakan sebelumnya antara lain (Perpres Republik Indonesia, 2005) no. 77 tentang penetapan pupuk bersubsidi sebagai barang dalam pengawasan, UU no. 19 tahun (2013) tentang perlindungan dan pemberdayaan petani khususnya di pasal 3, dimana perlindungan dan pemberdayaan petani ini dilakukan dengan menyediakan sarana dan prasarana pertanian yang dibutuhkan dalam upaya pengembangan usaha tani. Biroinfrasda (2019), kartu tani merupakan kartu debit BRI kaertu elektronik yang berguna untuk mengetahui kuota atau jatah pupuk sesuai dengan luas lahan yang dimiliki. Pembayaran pupuk bersubsidi ini biasanya ditempatkan di pengecer yang menggunakan mesin Electronic Data Capture (EDC). Diharapkan dari program kartu tani pemerintah benar-benar dapat menyalurkan pupuk bersubsidi tepat sasaran. Dari beberapa permasalahan di atas, peneliti tertarik untuk menganalisis pengaruh Program kartu tani terhadap penurunan biaya pupuk di Desa Gulurejo Kecamatan Lendah Kabupaten Kulon Progo.

Pemberdayaan adalah proses dan tujuan. Sebagai proses pemberdayaan adalah rangkaian kegiatan untuk memperkuat daya atau pemberdayaan kelompok lemah dalam masyarakat (Mahendra, 2019). Pemerintah berdasarkan asas pemberdayaan petani membuat berbagai regulasi dan kebijakan yang 
sangat mendukung petani(Korten, 1981). Tujuan dari program kartu tani adalah terwujudnya penyaluran, pengendalian dan pengawasan pupuk bersubsidi kepada petani yang berhak menerima subsidi (Susila, 2010). Program Kartu Tani juga memiliki berbagai manfaat baik bagi pemerintah maupun petani. Program kartu tani yang dimulai pemerintah pada 1 September 2020 diharapkan bisa menjadi solusi bagi petani yang kesulitan mendapatkan terhadap mahalnya biaya pupuk. Penelitian ini bertujuan untuk menganalisis pengaruh penggunaan Kartu Tani terhadap penurunan biaya pupuk bagi petani padi. Penelitian ini berfokus pada pengujian biaya pemupukan bagi petani padi sebelum dan sesudah menggunakan kartu tani.

\section{METODE PENELITIAN}

\section{Lokasi Penelitian dan Pengambilan Sampel}

Jenis data yang digunakan dalam penelitian ini adalah data primer dan data sekunder. Data primer yang digunakan dalam penelitian ini berupa di dapatkan dari hasil pengumpulan kuesioner dan wawancara dilapangan. Data sekunder diperoleh dari pihak yang terkait dalam penelitian ini seperti kantor kecamatan, Dinas Pertanian dan penelitian terdahulu (Creswell, 2016).

Penentuan lokasi dilakukan secara purposive yang didasarkan pada kriteria lokasi, Kabupaten/Kota yang telah melaksanakan program dan realisasi program kartu tani. Penelitian ini dilakukan di Desa Gulurejo, Kecamatan Lendah, Kabupaten Kulon Progo, D.I Yogyakarta. Lokasi penelitian dipilih karena realisasi pengguna awal kartu tani yang tinggi. Penentuan jumlah sampel untuk mengetahui persepsi petani terhadap implementasi kartu tani dilakukan secara sengaja atau purposive yaitu petani yang sudah memiliki kartu tani dan telah mengimplementasikan kartu tani di lokasi penelitian. Jumlah sampel yang digunakan dalam penelitian adalah 27 orang hal ini didasarkan pada komoditas yang diusahakan dan luas lahan yang diusahakan. Keseragaman luas lahan menjadi penting karena padal luas lahan yang sama kebutuhan pupuk pun tidak akan jauh berbeda.

Penelitian ini dilaksanakan pada bulan Desember 2020 hingga Februari 2021. Penelitian ini menggunakan metode wawancara bertarget menggunakan kuesioner terstruktur.

\section{Analisis Data}

Dalam penelitian ini digunakan analisis deskriptif (uji non parametric), yaitu dengan mengemukakan hasil wawancara dan kuisioner dari responden. Kemudian untuk membuktikan hipotesis penelitian bahwa terdapat perbedaan biaya pupuk sebelum dan setelah program kartu tani dengan Uji Wilcoxon. 
Parameter yang diuji pada penelitian ini adalah biaya pupuk dari 27 sampel sebelum dan sesudah program kartu tani. Selanjutnya dianalisis menggunakan uji Wilcoxon. Uji wilcoxon signed test merupakan uji nonparametris yang digunakan untuk megukur perbedaan 2 kelompok data berpasangan berskala ordinal atau interval tetapi data berdistribusi tidak normal dengan asumsi 27 data sample belum memenuhi normalitas data. Menggunakan taraf signifikansi sebesar 5\% dan dilakukan menggunakan bantuan software SPSS. Rumus uji wilcoxon sign rank test adalah sebagai berikut (Cooper \& Schindler, 2014):

$$
Z=\frac{t-\mu T}{\sigma T} \mu T=\frac{n(n-1)}{4} \sigma T=\sqrt{\frac{n(n+1)(2 n+1)}{24}}
$$

Keterangan: T=Jumlah rank dengan tanda paling kecil

Pengambilan keputusan pada uji Wilcoxon dapat menggunakan uji Z. Dasar pengambilan keputusan dengan uji $Z$ yaitu :

(1) Jika Zhitung< Ztabel maka H0 diterima, tidak ada perbedaan biaya pupuk antara sebelum dengan sesudah program kartu tani,

(2) Jika Zhitung> Ztabel maka H1 diterima, ada perbedaan biaya pupuk antara sebelum dengan sesudah program kartu tani.

\section{HASIL DAN PEMBAHASAN}

Biaya yang diteliti adalah biaya pembelian pupuk kimia antara lain; Phonska, TSP dan Urea. Biaya pupuk organik dan pupuk kimia lainya yang tidak disebutkan diatas maka tidak diteliti dalam penelitian ini. Penurunan biaya yang dimaksudkan dalam penelitian ini adalah turunya biaya pupuk petani padi setelah mengikuti program kartu tani. Jika dilihat dari analisis deskriptif terlihat bahwa terjadi penurunan rata-rata biaya pupuk sebesar Rp. 1.316.296 dari biaya Rp. 2.032.592 menjadi Rp. 716.296.

Tabel 1. Analisis Deskriptif

\begin{tabular}{lrrrrr}
\hline & N & Minimum Maximum & Mean & \multicolumn{1}{c}{$\begin{array}{c}\text { Std. } \\
\text { Deviation }\end{array}$} \\
\hline Sebelum Program & 27 & 1800000 & 2500000 & 2032592.59 & 158580.302 \\
Sesudah Program & 27 & 650000 & 800000 & 716296.30 & 36177.782 \\
Valid N (listwise) & 27 & & & & \\
\hline
\end{tabular}

Sumber : Data Primer Diolah, 2021

Biaya usahatani padi bisa mencapai Rp. 9.612 .356 per hektar, dengan rata-rata biaya pemupukan mencapai Rp. 2.546.265,48 per hektar. Sedangkan menurut Gallagher et. al, (1991), jumlah pupuk untuk padi adalah urea kebutuhan 250 kg/hA, dengan hargaRp 2.200/Kg, NPK kebutuhan 100 kg/hA 
dengan harga Rp 2.400/Kg, TSP kebutuhan $2.000 \mathrm{~kg} / \mathrm{hA}$ dengan harga Rp $500 / \mathrm{Kg}$, sehingga total biaya pupuk adalah Rp 1.790.000 . Dalam penelitian ini, total biaya pupuk yang dikeluarkan oleh petani yang menggunakan program kartu tani adalah sebesar Rp. 716.296. Sehingga dapat dikatakan penurunan biaya pemupukan yang terjadi pada petani padi yang menggunakan kartu tani lebih rendah dibandingkan dengan petani padi yang tidak menggunakan program kartu tani. Perbedaan biaya pemupukan yang dikeluarkan petani padi tentunya akan berdampak pada biaya produksi petani padi.

Tabel 2 Uji t

\begin{tabular}{lcccc}
\hline & & N & Correlation & Sig. \\
\hline Pair 1 & $\begin{array}{c}\text { Sebelum Program \& } \\
\text { Sesudah Program }\end{array}$ & 27 & .388 & .045 \\
\hline
\end{tabular}

Sumber : Data Primer Diolah, 2021

Hasil Uji t menunjukkan perbandingan biaya yang dikeluarkan petani sebelum program Kartu Tani dan setelah program Kartu Tani, hal ini terlihat dari nilai Sig. 0,045 atau $<0,05$. Hasil uji t dapat dikatakan bahwa penurunan biaya pemupukan cukup signifikan. Dalam penelitian ini, hasilnya menunjukkan penurunan biaya pupuk yang signifikan karena petani di Kabupaten Kulon Progo mendapatkan harga yang sesuai dengan harga yang ditetapkan pemerintah. Temuan ini bertolak belakang dengan hasil penelitian (Adnyana dan Mokhtar, 2019) yang menyebutkan bahwa harga pupuk bersubsidi yang diterima petani berbeda dengan harga yang ditetapkan. Hasil penelitian ini juga bertentangan dengan pendapat (Holden \& Lundeka, 2010) yang menyatakan bahwa rata-rata harga beli pupuk bersubsidi di Malawi juga di atas harga yang seharusnya karena ada petani yang membeli dengan harga penuh atau tidak mendapatkan subsidi kupon pupuk.

Hasil analisis Wilcoxon menunjukkan bahwa seluruh responden mengalami penurunan biaya pemupukan. Hal ini terlihat dari hasil negative ranks yaitu sebanyak 27 dari total 27 responden. Program Kartu Tani gelombang pertama di Desa Gulurejo Kecamatan Lendah Kabupaten Kulon Progo dengan responden 27 orang petani yang menggarap sawah dengan komoditas padi bisa dikatakan berhasil menekan biaya pupuk kimia. Keberhasilan program kartu tani dalam penelitian ini karena petani mudah mendapatkan edukasi dari pemerintah dan instansi terkait. Pada dasarnya petani padi di Kulon Progo sudah tidak asing lagi dengan dunia perbankan, sehingga ketika pemerintah mencanangkan program kartu tani berbasis perbankan, petani bisa beradaptasi dengan cepat. Hal ini sejalan dengan penelitian Moko, et al. (2017) yang mengatakan bahwa edukasi dan literasi terkait perbankan perlu didorong agar petani lebih bankable.

416 | Bayu Mahendra, Suprapto dan Hima Barima: Pengaruh Program... 
Tabel 3. Uji Wilcoxon Sebelum Dan Sesudah Mengikuti Program Kartu Tani

\begin{tabular}{llrrr}
\hline & & \multicolumn{2}{c}{ N } & Mean Rank Sum of Ranks \\
\hline & Negative Ranks & $27 \mathrm{a}$ & 14.00 & 378.00 \\
SesudahProgram- & Positive Ranks & $0 \mathrm{~b}$ & .00 & .00 \\
Sebelum Program & Ties & $0 \mathrm{c}$ & & \\
& Total & 27 & & \\
\hline
\end{tabular}

Sumber : Data Primer Diolah, 2021

Sarana dan prasarana di Kabupaten Kulon Progo turut mempengaruhi keberhasilan program kartu tani. Dari temuan di lapangan, akses petani terhadap pupuk sangat mudah dan tidak pernah terkendala cuaca. Seluruh jalan menuju persawahan dan agen pupuk telah terhubung dengan baik sehingga petani tidak perlu mengeluarkan biaya tambahan untuk mengakses pupuk bersubsidi. Jika dibandingkan dengan hasil penelitian (Ashari dan Hariani, 2019) tentang efektivitas program kartu tani di Kabupaten Banjarnegara yang menyimpulkan bahwa program kartu tani di Kabupaten Banjarnegara belum berhasil dan tidak efektif dari segi ketersediaan fasilitas dan infrastruktur, faktor lingkungan, dan sistem pengendalian dan pengawasan yang ada pendidikan. Sehingga dalam penelitian ini dapat dikatakan bahwa program kartu tani di Kabupaten Kulon Progo berhasil karena didukung oleh sarana dan prasarana yang baik, sumber daya manusia yang cepat beradaptasi dan juga faktor lingkungan yang mendukung berjalannya program kartu tani.

Penurunan biaya pupuk yang terjadi pada petani padi di Desa Gulurejo Kecamatan Lendah Kabupaten Kulon Progo sebesar Rp 1.316.296. Hal ini tentunya berdampak pada peningkatan pendapatan petani. Dengan demikian, penggunaan kartu tani untuk menekan biaya pemupukan dapat dikatakan telah berhasil. Program kartu tani penting untuk menekan biaya pupuk karena petani dapat mengakses pupuk bersubsidi dengan lebih mudah, petani dapat mengetahui jumlah pupuk yang dibutuhkan, dan petani mendapatkan pupuk dengan harga yang lebih murah. Sebagian besar petani padi di Desa Gulurejo masih bergantung pada pupuk nonsubsidi sebelum program kartu tani diperkenalkan, sehingga biaya yang dikeluarkan petani menjadi lebih tinggi. Kelangkaan pupuk bersubsidi menjadi penyebab utama petani sulit keluar dari permasalahan pupuk, namun sejak mengikuti program kartu tani petani mendapatkan pupuk yang dibutuhkan dan ketersediaannya selalu terjamin.

Responden dalam penelitian ini secara keseluruhan mengalami penurunan biaya pemupukan, program kartu tani yang dilaksanakan di Desa Gulurejo, Lendah, Kabupaten Kulon Progo dapat dikatakan berhasil dan dapat diimplementasikan di daerah lain di seluruh Indonesia. Faktor keberhasilan program ini dikarenakan kecepatan adopsi di tingkat petani yang baik, hal ini seperti yang telah diungkapkan oleh (Jorgi, dkk, 2019) yang mengatakan bahwa 
motivasi, keterlibatan tokoh masyarakat dan kebijakan pemerintah mempengaruhi inovasi teknologi. Kebersamaan dan tingkat budaya yang sama juga mempengaruhi adopsi teknologi hal ini sejalan dengan hasil penelitian (Fagi, 2008). Faktor sarana dan prasarana serta topografi lingkungan yang tidak terlalu berbukit mendukung pelaksanaan program kartu tani di Kabupaten Kulon Progo. Ini sesuai dengan hasil penelitian (Kurniawati dan Kurniawan, 2018) yang menyatakan bahwa masyarakat petani di daerah dengan topografi berbukit, kurangnya sosialisasi menjadi kendala utama dalam penggunaan kartu tani. Menurut Kristianto, ((2015), (2021)), bentuk kegiatan partisipasi masyarakat Kulon Progo adalah menggerakkan sumber daya masyarakatnya. Salah satu cara untuk meningkatkannya ialah menggunakan sosialisasi yang efiektif kepada masyarakat petani padi. Peran penyuluh sangat penting dalam meningkatkan penyerapan program dan partisispasi masyarakat (Kustiari et al., 2012; Mulya \& Moita, 2018; Nefri, 2018; Rintjap, 2018; Saefudin, 2016).

Penurunan biaya pupuk yang terjadi pada seluruh responden yang diteliti dikarenakan semua responden membeli pupuk dengan harga pupuk bersubsidi yang lebih murah dibandingkan dengan pupuk non subsidi. Bagi petani padi, pupuk merupakan salah satu faktor penting bagi kelangsungan dan keberhasilan tanaman padi. Dengan menggunakan kartu petani, petani memiliki akses yang mudah dan harga yang lebih murah. Program ini dapat mengurangi biaya pupuk bagi petani padi dan penurunan tersebut sangat bermanfaat untuk meningkatkan keuntungan petani.

\section{SIMPULAN DAN SARAN}

\section{Simpulan}

Program Kartu Tani yang dilaksanakan pemerintah atas dasar perlindungan dan pemberdayaan petani di Desa Gulurejo Kecamatan Lendah Kabupaten Kulon Progo D.I Yogyakarta dapat dikatakan berhasil menekan biaya pembelian pupuk kimia oleh petani. Dari 27 responden yang diteliti, hasil analisis menunjukkan bahwa 100\% responden mengalami penurunan biaya pembelian pupuk kimia, pupuk yang dimaksud adalah sebagai berikut; Phonska, TSP dan Urea. Hasil uji statistik juga menunjukkan bahwa penurunan biaya pupuk bagi petani padi dapat dikatakan signifikan.

\section{Saran}

Dengan keberhasilan program kartu tani dalam menekan biaya pupuk yang harus ditanggung petani padi, maka program Kartu Tani perlu diperluas dan diterapkan pada komoditas lain. Program kartu tani juga dapat diterapkan pada perkebunan dengan kebutuhan pupuk yang besar sehingga petani perkebunan juga dapat lebih mudah mengakses pupuk bersubsidi dan mendapatkan hasil yang baik dalam usahanya di bidang pertanian.

418 | Bayu Mahendra, Suprapto dan Hima Barima: Pengaruh Program... 


\section{DAFTAR PUSTAKA}

Adnyana, I. P., \& Mohktar, M. S. 2019. Optimalisasi Kinerja Sistem Distribusi Pupuk Bantuan Pemerintah di Provinsi NTB. SOCA: Jurnal Sosial Ekonomi Pertanian. 13 (2): 201-217

Agus. D. N., Abi. P. S., Erlinda. A., Yahya. S., dan Julia. I. K. 2018. Distribusi Pupuk Bersubsidi di Kabupaten Bantul Provinsi Daerah Istimewa Yogkayakarta. Jurnal Sosial Ekonomi Pertanian. 2(1): 70 - 82.

Ashari, M. L., \& Hariani, D. 2019. Analisis efektivitas program kartu tani di Kecamatan Banjarnegara. Kabupaten Banjarnegara. Journal of Public Policy and Management Review. 8 (2): 1-21

Badan Pusat Statistik. 2019. Kabupaten Kulon Progo dalam Angka 2019. Kulon Progo: BPS.

Creswell, Jhon W. 2016. Research Design Pendekatan Kualitatif, Kuantitatif, dan Mixed. Yogyakarta: Pustaka Pelajar.

Darwis V, dan Saptana. 2010. Rekonstruksi kelembagaan dan uji teknologi pemupukan kebijakan strategis mengatasi kelangkaan pupuk. Analisis Kebijakan Pertanian. 8(2): 167-186.

Fagi, A. M. 2008. Alternatif Teknologi Peningkatan Produksi Beras Nasional. Iptek Tanaman Pangan. 1(1): 9-26.

Gallagher, K., Elsa R., Remi Ag., Latifa N dan John P. 1991. Petunjuk Percobaan Lapangan Musim PHT Padi: Program Nasional Pelatihan dan Pengembangn PHT. Jakarta: Bappenas.

Holden, S., \& Lunduka, R. 2010. Impacts of the Fertilizer Subsidy Programme in Malawi: Targeting, Household Perceptions and Preferences. Norway: Norwegian University of Life Sciences.

Jorgi, R.S., Gayatri, S., \& Dalmiyatun, T. 2019. Hubungan Tingkat Pengetahuan Petani ddengan Efektivitas Pelaksanaan Program Kartu Tani di Kabupaten Semarang. AGRARIS: Journal of Agribusiness and Rural Development Research. 5 (2): 89 -98.

Kustiari, T., Sumardjo, Slamet, M, Tjitropranoto, P. 2012. Pengaruh Efektivitas Penyuluhan Terhadap Kompetensi Pembudidaya Rumput Laut Polikultur Di Perairan Pantai Utara Pulau Jawa. J. Sosek KP. 7(1): 79-85

Kristianto, F. A. N. 2015. Partisipasi Masyarakat Kecamatan Kalibawang dalam Gerakan "Bela-Beli Kulon Progo". SOCA: Jurnal Sosial Ekonomi Pertanian. 12(1): $19-28$

Kristianto, I. I. N. 2021. Pemanfaatan Potensi Desa dan Penerapan Minapadi di Kawasan Pertanian Desa Janten, Kecamatan Temon, Kabupaten Kulon Progo, Yogyakarta. Jurnal Atmainovasia. 1(2): 117-121

Korten, D.C. 1981. Social Development: Putting People First. in Bureaucracy and the Poor: Closing the Gap, D.C. Korten and F.B. Alfonso(ed.). Manila: Mc Graw Hill International Book Company. 
Kurniawati, Kurniawan. 2018. Persepsi Masyarakat Penggunaan Kartu Tani di Kabupaten Pati (Kasus di Desa Wotan dan Desa Pakem, Kecamatan Sukolilo). Journal of Chemical Information and Modeling. 7(4):1-15

Mahendra, Bayu. 2019. Pemberdayaan Masyarakat Melalui Program Csr Pt. Angkasa Pura I Yogyakarta (Studi Kasus Umkm Madu Hutan Raya Dan Mina Kembar). Jurnal Agercolere. 1(2): 30-36.

Moko, K. W., Suwarto, \& Utama, B. W. (2017). Perbedaan persepsi petani terhadap program kartu tani di Kecamatan Kalijambe, Kabupaten Sragen. Journal of Sustainable Agriculture. 32 (1): 9-13

Mulya, L., Sidu, D., Moita, S. 2018. Efektivitas Komunikasi Penyuluh Pertanian Tanaman Jagung Di Kecamatan Sawerigadi Kabupaten Muna Barat. Jurnal Administrasi Pembangunan dan Kebijakan Publik. 8 (1): 1-9

Nefri, R. 2018. Efektivitas Penyuluhan Internal Perilaku Bermedia Sosial Bagi Remaja Islam Di Kota Medan. Jurnal Jurnalisme. 7(2): 174-188

Purnamaningsih, R. 2016. Induksi kalus dan optimasi regenerasi empat varietas padi melalui kultur in vitro. Jurnal AgroBiogen. 2 (2): 74-80.

Rintjap, Katrin, A. 2018. Efektivitas Komunikasi Dalam Penerimaan Informasi Pada Kelompok Peternak Sapi Potong di Kecamatan Remboken Kabupaten Minahasa Sulawesi Utara. Pros Sem Nas Masy Biodiv Indon.1 (7): 1711-1714

Sikumbang, A. T., Effendy, E., Husna, U. 2019. Efektifitas Komunikasi Persuasif Penyuluh Agama Islam Dalam Pembinaan Majelis Taklim Kota Langsa. AT-BALAGH. 3(1):30-46

Subowo, G. 2009. Potensi Pengembangan Komoditas Pertanian Bernilai Ekonomi Tinggi Di Daerah Istimewa Yogyakarta. Jurnal Sumberdaya Lahan. 3 (1): 39-47.

Susila, W. R. (2010). Kebijakan Subsidi Pupuk: Perlu Ditinjau Kembali. Jurnal Litbang Pertanian. 29 (2): 43-49.

Ustriyana, I.N.G. 2015. Agribusiness Model in Rural Community Economic. African Journal of Agricultural Research. 10(4):174-178

\section{Peraturan Perundangan}

Peraturan Menteri Pertanian (Permentan) No 10 Tahun 2020 tentang Alokasi dan Harga Eceran Tertinggi Pupuk Bersubsidi Sektor Pertanian Tahun Anggaran 2020

Perpres Republik Indonesia, No 77 Tahun 2005. Tentang Penetapan Pupuk Bersubsidi Sebagai Barang Dalam Pengawasan

Undang-Undang Nomor 20 Tahun 2019 tentang Anggaran Pendapatan dan Belanja Negara Tahun Anggaran 2020

Undang-Undang Nomor 19 tahun 2013 tentang Perlindungan dan Pemberdayaan petani 